\title{
Preparação e caracterização de materiais Absorventes a base de glicerina e caulim de Caraí - Minas Gerais - Brasil
}

\author{
Preparation and characterization of absorbent \\ materials based on glycerine and kaolin from caraí \\ - Minas Gerais - Brasil
}

Wilker Tagner do Nascimento Mendes ${ }^{1}$, Juan Pedro Bretas Roa ${ }^{1}$, Edivaldo dos Santos Filho ${ }^{1}$

\begin{abstract}
${ }^{1}$ Universidade Federal dos Vales do Jequitinhonha e Mucuri - UFVJM. Instituto de Ciência e Tecnologia - ICT - Programa de Pós-graduação em Biocombustíveis, Rodovia MGT 367 - Km 583, nº 5.000, Alto da Jacuba, CEP: 39100-000, Diamantina, Minas Gerais, Brasil.

e-mail: wilker.mendes@yahoo.com.br,juan.roa@ict.ufvjm.edu.br, edivaldo.santos@ict.ufvjm.edu.br
\end{abstract}

\section{RESUMO}

A produção de materiais absorvedores de água é um grande desafio para diversas aplicações nos setores agrícola, industrial, de energia, entre outros. No presente trabalho, foram preparados materiais a partir da reação de glicerina, caulim e ácido succínico, tendo ácido sulfúrico como catalisador. Foram utilizadas três razões molares para a mistura caulim:ácido succínico, 1:0, 1:1 e 0:1. Foram preparados materiais também em uma reação com o auxílio do Dean-stark, onde foram preparadas três amostras. Foram produzidos filmes de amido para facilitar a aplicação dos materiais obtidos. O FTIR confirmou a polimerização do ácido succínico com a glicerina, e a ancoragem do mesmo ao caulim. O que também pode ser evidenciado através do DRX. Os testes de absorção mostram que o material produzido pode ser utilizado como material absorvente, absorvendo cerca de $50 \mathrm{~g}$ de água por g de amostra.

Palavras-chave: Glicerina; Caulim; Ácido Succínico; Material Absorvente.

\begin{abstract}
The production of water-absorbing materials is a major challenge for several applications in the agricultural, industrial and energy sectors, among others. In the present work, materials were prepared from the reaction of glycerin, kaolin and succinic acid, with sulfuric acid as a catalyst. Three molar ratios were used for the kaolin mixture: succinic acid, 1: 0, 1: 1 and $0: 1$. Materials were also prepared in a reaction with the aid of Dean-stark, where three samples were prepared. Starch films were produced to facilitate the application of the materials obtained. The FTIR confirmed the polymerization of succinic acid with glycerin, and its anchoring to kaolin. What can also be evidenced through the DRX. Absorption tests show that the material produced can be used as an absorbent material, absorbing about $50 \mathrm{~g}$ of water per $\mathrm{g}$ of sample.
\end{abstract}

Keywords: Glyrecin; Kaolin; Succinic Acid; Absorbent Material.

\section{INTRODUÇÃO}

O grande consumo de combustíveis fósseis aliado aos seus efeitos nocivos ao meio ambiente e por serem reservas finitas, são os principais motivos que tornam indispensável a substituição destes combustíveis por outros que tenham como base a utilização de biomassa (matéria orgânica renovável), ou seja, combustíveis que derivem de fonte renovável, limpa, biodegradável, não tóxica ao meio ambiente e viável economicamente [1]. Estes são chamados de biocombustíveis e podem substituir total ou parcialmente os combustíveis fósseis em motores de combustão interna e em outras formas de geração de energia [2].

Pensando na substituição do diesel do petróleo, surge o biodiesel, um combustível que pode ser obtido a partir de óleos vegetais, gordura animal e óleos residuais [3]. O principal método de obtenção do biodiesel é através da transesteri- 
ficação de uma fonte de triglicerídeos (óleo ou gordura) com um álcool de cadeia curta na presença de um catalisador [4]. Além do biodiesel, um dos subprodutos obtidos através desta reação é o glicerol [5, 6], este coproduto é obtido como cerca de $10 \%$ do volume de biodiesel obtido [7].

Desde 2003 a adição de biodiesel ao diesel de petróleo passou a ser facultativa no mercado brasileiro, mas desde 2008 há a adição obrigatória de 2\% e em 2019 este valor passou para 11\% [9], espera-se um aumento na produção deste biocombustível e consequentemente, do glicerol. O glicerol pode ser caracterizado como um composto na forma impura, que pode apresentar aproximadamente $20 \%$ de impurezas, tais como água, catalisador, sais, álcool não reagido, vestígios de triglicerídeos não reagidos, entre outros compostos [10,11]. O termo glicerina por sua vez é utilizado para o composto que possui $95 \%$ de pureza [10]. Sendo assim, é necessário o desenvolvimento de nova tecnologia que vise a utilização do glicerol com o mínimo de tratamento prévio, a fim de aumentar sua empregabilidade [10].

Entretanto, novas tecnologias que utilizem a glicerina ampliam também a capacidade de utilização do coproduto da Indústria de Biodiesel, favorecendo sua cadeia produtiva e criando cenários cada vez mais favoráveis para ampliar a quantidade de biodiesel nos postos de gasolina.

No Brasil, observa-se também uma grande produção de caulim, um argilomineral, composto basicamente por caulinita $\left(\mathrm{Al}_{2} \mathrm{Si}_{2} \mathrm{O}_{5}(\mathrm{OH})_{4}\right)$ com grande aplicação devido ao seu baixo custo e a grande disponibilidade [12]. O caulim é amplamente utilizado pela indústria do papel (cerca de $47 \%$ da produção mundial) [13] seja para cobertura (coating) ou carga (filler) $[14,15]$. Estima-se que as reservas nacionais deste mineral são da ordem de 5 bilhões de toneladas [15], e com isso, tem-se uma grande oferta de caulim disponível no mercado, cujo volume de produção no Brasil foi de 1.810 .000 toneladas no ano de 2015 [16].

Nesse contexto, o objetivo deste presente trabalho foi realizar a modificação da superfície do caulim utilizando ácido succínico e glicerina desenvolvendo um material que apresente capacidade de ser utilizado como absorvedor de água.

\section{EXPERIMENTAL}

O caulim utilizado para o procedimento experimental foi fornecido pela MBM Minérios, uma minerdora situada na zona rural da cidade de Caraí, Minas Gerais. O caulim fornecido possuía a seguinte compôs ção: $\mathrm{SiO} 2$ 46,30\%, Al2O3 38,70\%, Fe2O3 0,15\% e $\mathrm{TiO} 2$ 0,06\% [12].

Para a caracterização dos produtos foi utilizado um equipamento Thermo Scientific, modelo Nicolet 6700 acoplado a um módulo para reflectância total atenuada, ATR, entre 4000 e $400 \mathrm{~cm}-1$, janela de Germâ-nio, 32 varreduras e resolução de $4 \mathrm{~cm}$-1. Para se realizar a análise dos dados foi utilizado um software para a geração dos gráficos.

A mistura entre o caulim e ácido succínico (Dinâmica Química Contemporânea, 99,5\% de pureza) foi preparada na proporção molar de 4:1. Foram conduzidas reações utilizando $10 \mathrm{~g}$ da mistura caulim: ácido succínico (4:1) $\mathrm{cm} 100 \mathrm{~mL}$ de água destilada e foi utilizado uma solução $1 \% \mathrm{~m} / \mathrm{m}$ de ácido sulfúrico (Neon Comercial, pureza entre 95 e $98 \%$ ) como catalisador, em relação à massa total da mistura, nos tempos de 0, 30, 60, 90 e 180 minutos. Os processos foram feitos em duplicata e o produto final foi filtrado a vácuo. Após a filtração, a solução produzida foi separada em duas partes, o retido foi nomeado como $\mathrm{F}$ e o permeado foi nomeada por S. Após o processo de filtração da solução, as amostras $\mathrm{F}$ e $\mathrm{S}$ foram colocadas em uma placa de petri, pesadas e levadas para uma estufa e mantidas a $100^{\circ} \mathrm{C}$ por 24 horas a fim de se eliminar toda a água presente na amostra. Com as amostras secas, foram separadas pequenas quantidades delas para realizar a análise no espectrofotômetro. Ao final foram gerados 10 produtos cuja denominação foi definida como RSX e RFX, sendo X o número relativo ao tempo em que a reação ocorre, os produtos são apresentados pela Tabela 1 .

Tabela 1: Amostras RF e RS produzidas

\begin{tabular}{c|c}
\hline Nome da Amostra & Tempo Reacional (minutos) \\
\hline R0S & 0 \\
\hline R0F & 0 \\
\hline R1S & 30 \\
\hline R1F & 30 \\
\hline R2S & 60 \\
\hline R2F & 60 \\
\hline R3S & 90 \\
\hline R3F & 90 \\
\hline R4S & 180 \\
\hline
\end{tabular}




\begin{tabular}{c|c}
\hline R4F & 180 \\
\hline
\end{tabular}

Um segundo experimento foi conduzido, adicionando glicerina PA (Dinâmica Química Contemporânea, 99,50\%) ao

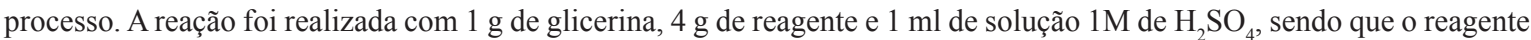
era composto de caulim + ácido succínico e teve sua composição variando em 1:1, 1:0 e 0:1, sendo a composição igual em $\% \mathrm{~m} / \mathrm{m}$ de caulim e ácido succínico. Assim, a reação foi realizada em dois intervalos de tempos, 30 e 180 minutos. As amostras produzidas neste segundo experimento foram nomeadas como GY:Z_T onde Y corresponde a fração de caulim e $\mathrm{Z}$ a fração de ácido succínico (podendo ser 1 ou 0) e T ao tempo reacional (30 e 180 minutos). As amostras e sua respectiva nomenclatura é apresentada pela Tabela 2.

Tabela 2: Amostras produzidas GY:Z_T

\begin{tabular}{cc}
\hline Nome da Amostra & Tempo Reacional (minutos) \\
\hline G1:1_30 & 30 \\
\hline G1:0_30 & 30 \\
\hline G0:1_30 & 30 \\
\hline G1:1_180 & 180 \\
\hline G1:0_180 & 180 \\
\hline G0:1_180 & 180 \\
\hline
\end{tabular}

Após a produção das amostras GY:Z_T, foram feitos testes em triplicata da absorção de água destes materiais, a fim de se avaliar se eles serão eficazes para a utilização como material filtrante do biodiesel. Inicialmente foi feito uma análise de porcentagem de absorção de água somente pelo algodão, e posteriormente, adicionado a amostra. Os testes foram realizados utilizando uma massa de algodão, aproximadamente $0,1 \mathrm{~g}$, uma massa de água, aproximadamente $1,0 \mathrm{~g}$, e uma pequena quantidade de material produzido, aproximadamente $0,02 \mathrm{~g}$. Foram montadas colunas para a filtração com o auxílio de uma ponteira de micropipeta. $\mathrm{O}$ algodão foi colocado no fundo da ponteira, sobre ele a amostra e foi adicionado a massa de água e no final avaliado a quantidade retida.

Após o teste de absorção de água, foi realizada uma análise estatística dos resultados obtidos. Para esta análise, foi utilizado o software $\mathrm{R}^{\circledR}$ [19], para se comparar as médias de dois grupos independentes (produtos com 30 e 180 minutos de reação). Para esta análise, inicialmente foi aplicado o teste de Shapiro-Wilk para se analisar a normalidade dos dados. Posteriormente foi realizado o teste de $\mathrm{t}$ de Student, onde se compara o p-valor obtido com o nível de significância para avaliar se as médias são estatisticamente iguais.

\section{RESULTADOS E DISCUSSÃO}

As amostras apresentadas pela Tabela 1 foram caracterizadas como materiais sólidos de cor branca, com distintas características. As amostras RXS apresentaram-se na forma de um filme quebradiço, que após recolhido foi previamente triturado; enquanto as amostras RXF apresentaram-se na forma de pó branco. As amostras de caulim e do ácido succínico também são sólidos brancos, como apresentado pela Figura 1 (a) e (b), respectivamente.
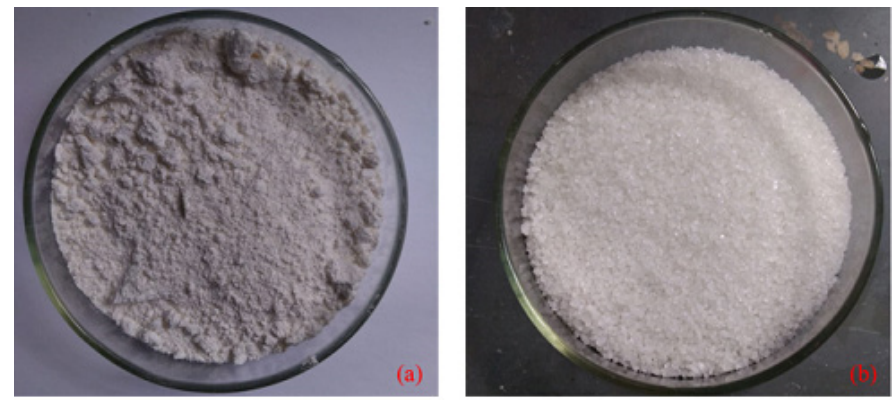

Figura 1: Caulim fornecido pela MBM e utilizado nas reações (a) e Ácido Succínico utilizado no processo reacional (b) 
Todas as amostras com designação S apresentam-se semelhantes visualmente ao Ácido Succínico, enquanto as amostras com designação F têm semelhança ao caulim, como pode ser visto na Figura 2 (a) e (b), respectivamente. Como forma de verificar se a superfície de ambos os compostos utilizados como precursores foram modificadas, esses produtos foram submetidos à análise por infravermelho (FTIR).
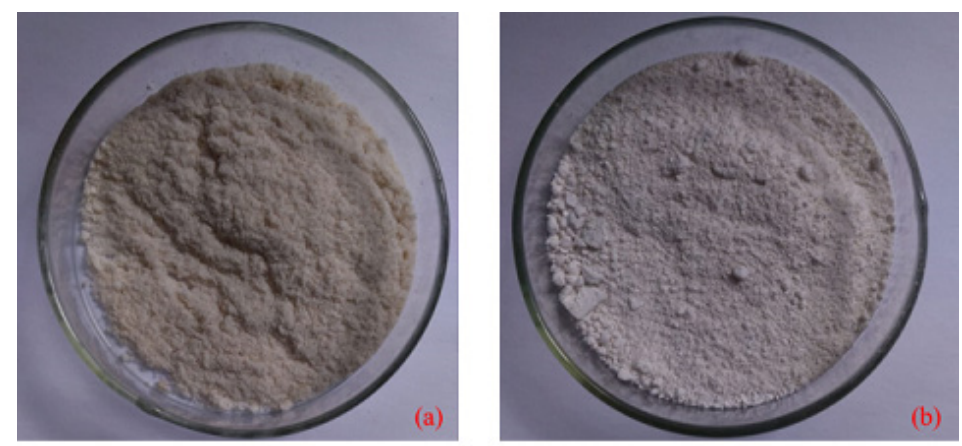

Figura 2: Produto reacional RS (a) e produto reacional RF (b)

São observadas algumas bandas específicas no espectro obtido do caulim que podem ser comparadas a valores da literatura, como apresentado na Tabela 3. O mesmo pode ser afirmado para o ácido succínico, cujos valores são apresentados na Tabela 4.

Tabela 3: Frequências específicas do Caulim

\begin{tabular}{c|c|c|c}
\hline Frequência obtida & Frequência $\mathbf{~ c m}^{-1}$ [15] & Frequência $\mathbf{~ c m}^{-1}$ [16] & Descrição \\
\hline 3689 & 3661 & 3689 & Estiramento OH \\
\hline 3623 & 3624 & 3621 & Estiramento OH \\
\hline 1626 & 1634 & 1642 & Deformação flexão água \\
\hline 1022 & 1031 & 1023 & Estiramento Si-O \\
\hline 915 & 915 & 912 & Deformação OH \\
\hline 794 & 840 & 795 & Deformação OH \\
\hline 683 & 693 & 690 & Si-O \\
\hline 669 & 673 & 687 & Si-O-Si \\
\hline
\end{tabular}

Tabela 4: Frequências específicas do Ácido Succínico

\begin{tabular}{c|c|c|c}
\hline Frequência obtida & Frequência $\mathbf{~ c m}^{-1}[\mathbf{1 7 ]}$ & Frequência $\mathbf{~ c m}^{-1}[\mathbf{1 8}]$ & Descrição \\
\hline 1675 & 1720 & 1692 & Estiramento $\mathrm{C}=\mathrm{O}(\mathrm{COOH})$ \\
\hline 1320 & 1396 & 1307 & Estiramento C-O $(\mathrm{COO})$ \\
\hline 2630 & 2650 & $2500-3300$ & Estiramento $\mathrm{OH}$ \\
\hline 2927 & 2932 & $2534-2635$ & Estiramento $\mathrm{CH}$ \\
\hline
\end{tabular}

Considerando a análise dos espectros dos diferentes produtos, estes foram comparados tomando por base os valores normatizados das absorbâncias dos materiais, em função da banda mais intensa de cada espectro. Pode-se observar uma grande semelhança entre os espectros das amostras RXF e do caulim. Esse fato indica que o caulim ou sofreu alterações superficiais muito pequenas, imperceptíveis pela grande presença das bandas SI-OH e Al-OH presentes no caulim, ou não elas ocorreram. Nesse caso o FTIR não é capaz de apresentar informação confirmando a mudança da superfície das partículas de caulim, Figura 3. 


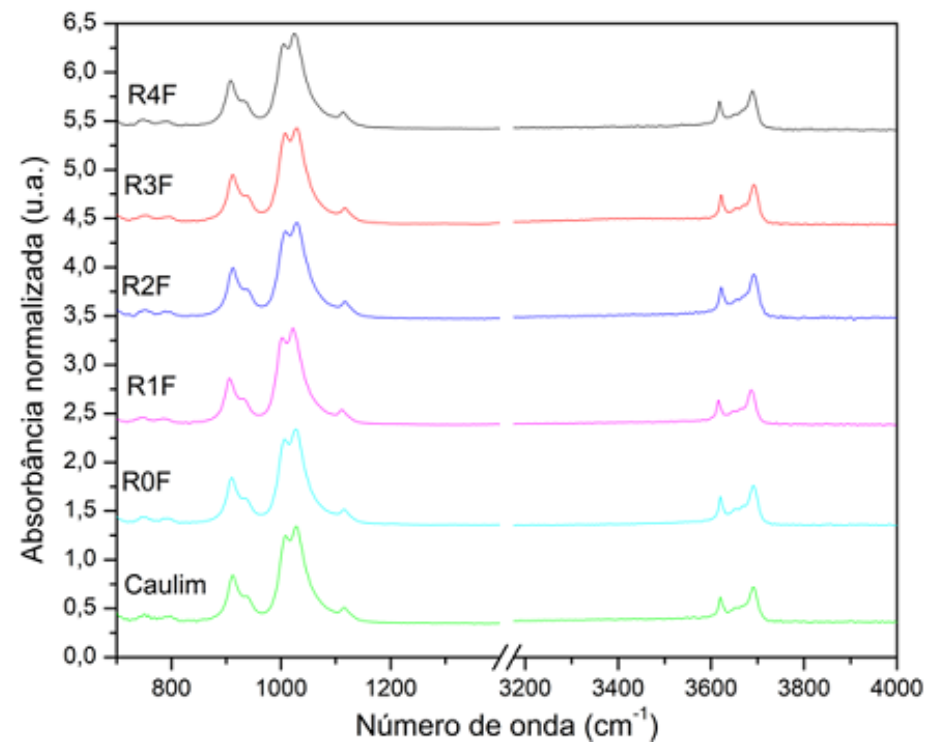

Figura 3: Espectro de FTIR das amostras de caulim e dos produtos RXF

No estudo das amostras RXS, foram observadas bandas características do ácido succínico em todos os produtos obtidos, especialmente pela banda característica do grupo COO- presente em $1675 \mathrm{~cm}^{-1}$, Figura 4.

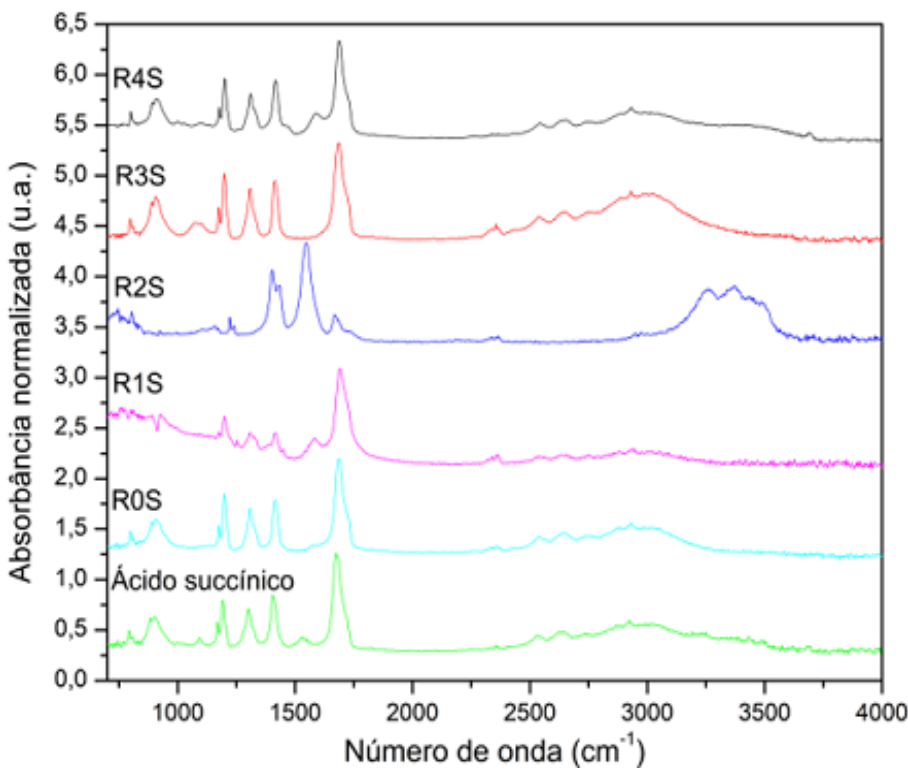

Figura 4: Espectro de FTIR das amostras de ácido succínico e dos produtos RXS

Entretanto, considerando a normalização dos espectros tomando a banda em $1675 \mathrm{~cm}^{-1}$ como referência, se observam aumentos relativos dos grupos:

- C-H (2800-3000 $\left.\mathrm{cm}^{-1}\right)$ : o aumento desta banda pode se dar devido à presença de matéria orgânica e também possível início de polimerização do ácido succínico, podendo ser evidenciado através da Figura 8, mostrando que houve modificação da superfície do ácido succínico através do dobramento das ligações $\mathrm{CH}_{2}$ com a diminuição (inexistência) da banda próxima a $1525 \mathrm{~cm}^{-1}[13,14]$;

- O-H (3300-3600 $\left.\mathrm{cm}^{-1}\right)$ : aumento na banda devido à presença de água e a presença dos grupos Si-OH e Al-OH que são provenientes do caulim, mostrando assim que houve a inserção do caulim na matriz do ácido succínico. Esta faixa é característica ácido carboxílico [13];

- C-O-C (1000-1150 $\left.\mathrm{cm}^{-1}\right)$ : o aumento desta banda indica polimerização e pode levar ao alargamento da banda de carbonila (COO-). Esta é uma banda típica de ésteres ${ }^{8}$; COO $\left(1675\right.$ e $\left.1700 \mathrm{~cm}^{-1}\right)$ : o aumento desta banda indica a 
formação de dímeros (dimerização), onde estes fazem com que a força do estiramento da ligação COO diminua sua frequência para esta banda [14]. Este processo de dimerização também é característico da polimerização.

As amostras obtidas com o segundo experimento, apresentadas pela Tabela 2, podem ser caracterizadas como materiais sólidos-poliméricos de cor branca, com distintas características. Considerando as amostras GY:Z_30, apresentam-se na forma de um material polimérico, quebradiço e branco. As amostras GY:Z_180, apresentam-se na forma de um material polimérico maleável e de cor branca. Os materiais produzidos são apresentados pelas Figuras 5 (a) e (b).
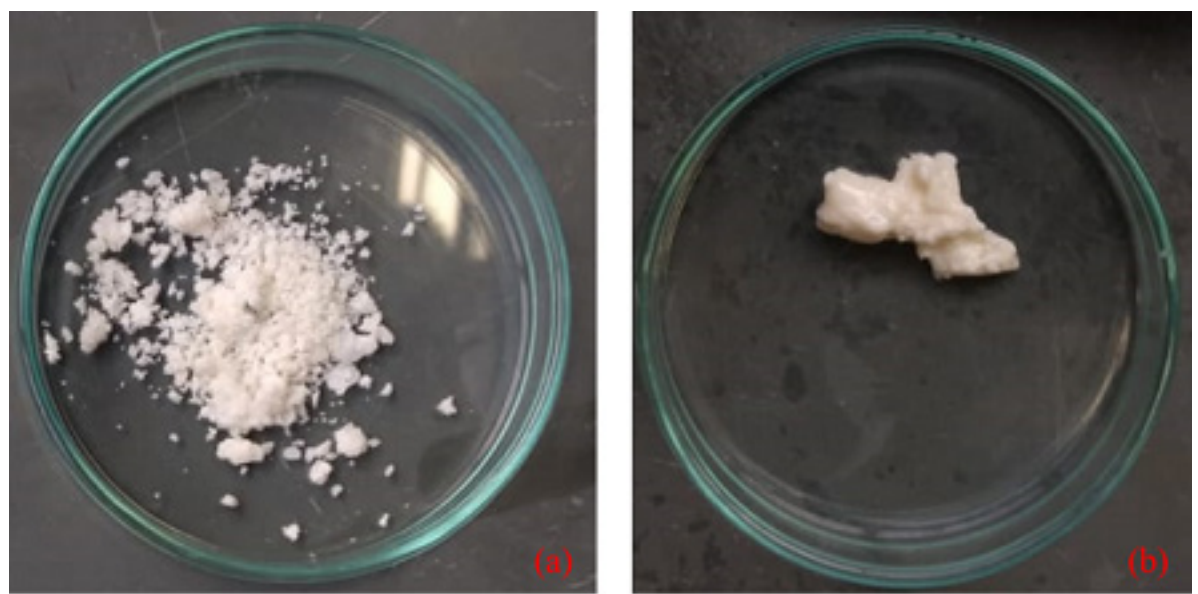

Figura 5: Produto reacional G1:1 30

A fim de se confirmar a modificação da superfície destas amostras, elas foram submetidas à análise por Infravermelho (FTIR). Para se fazer as análises dos gráficos de FTIR, eles foram divididos em três séries. A primeira analisada foi a série 1, composta pelas amostras G1:1 30, G1:1_180, caulim e ácido succínico. O gráfico desta séria é apresentada pela Figura 6 .

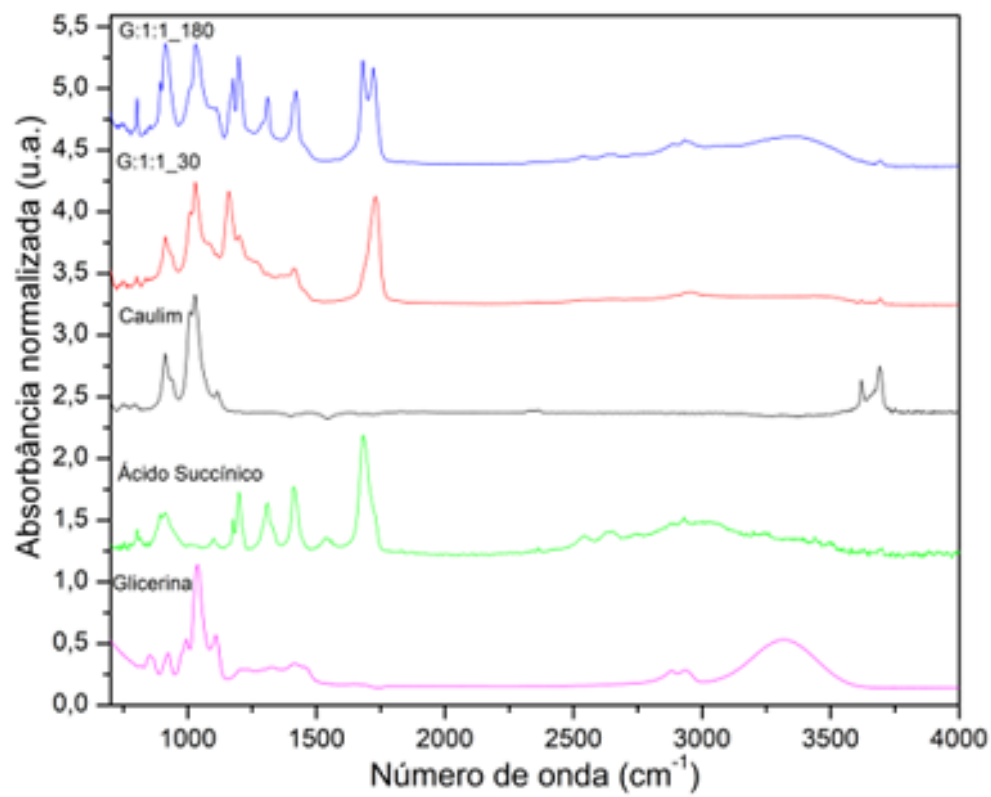

Figura 6: Espectros da Série 1

Ao observar os espectros da série 1, podemos fazer algumas indicações sobre determinadas bandas:

- em $3600 \mathrm{~cm}^{-1}$ : Existem grupos Si-OH e Al-OH que não reagiram em 30 minutos de reação, e ainda existe a presença também em 180 minutos $[15,16]$;

- em $3500 \mathrm{~cm}^{-1}$ : Podemos observar a existência de grupos $\mathrm{OH}$ provenientes da glicerina, em 30 e em 180 minutos de reação, sendo que são mais evidentes em 180 minutos; 
- em $1750 \mathrm{~cm}^{-1}$ : Existe a formação de grupos éster (em torno de $1728 \mathrm{~cm}^{-1}$ ), preferencialmente entre os grupos COOH do ácido succínico e da glicerina (30 minutos), com 180 minutos ocorre a reação entre os grupos terminais formados por glicerina-OH (chamado aqui por GLI-OH). Já com o ácido succínico (ou simplesmente AS) sustentando os grupos $\mathrm{COOH}$ como grupos terminais (180 minutos). Existem também os grupos $\mathrm{Si}-\mathrm{OH}$ e Al-OH que reagem com a glicerina $[17,18]$. Deste modo, estão presentes os seguintes grupos terminais, que variam de acordo com o tempo reacional e são apresentados através das Figuras 7 e 8.

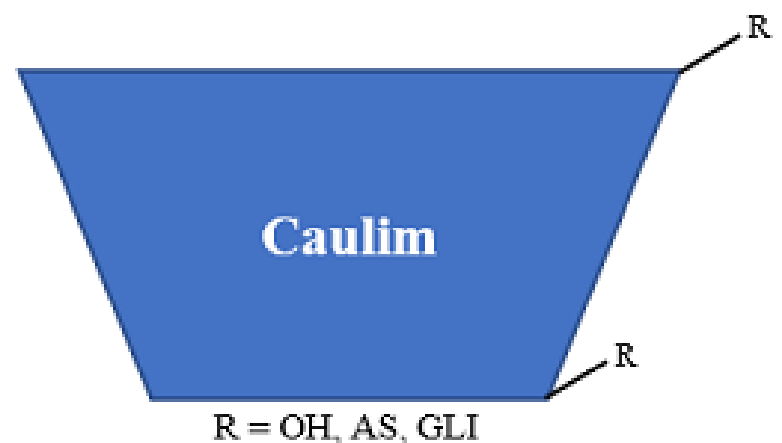

Figura 7: Proposta da estrutura do caulim com os grupos terminais adicionados pelo processo reacional em 30 minutos

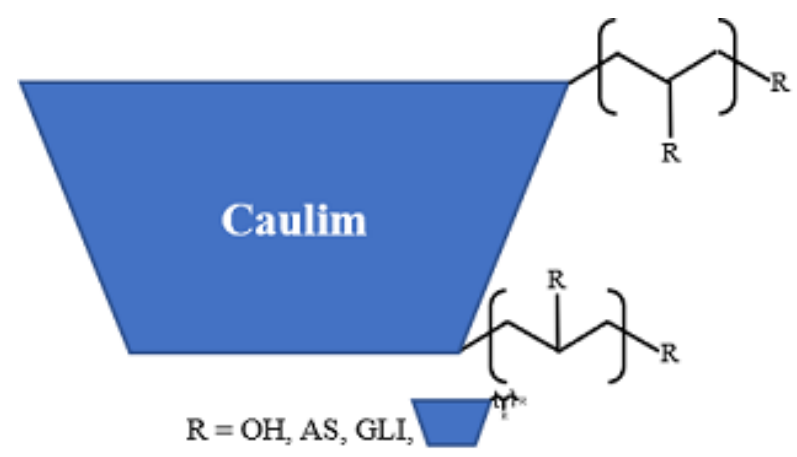

Figura 8: Proposta da estrutura do caulim com os grupos terminais adicionados pelo processo reacional em 180 minutos

- em $1200-100 \mathrm{~cm}^{-1}$ : indicam a presença de grupos CO, característicos grupos álcool, provenientes da glicerina [14];

Devido ao fato de haver menos ligações $\mathrm{OH}$ para o produto obtido em 30 minutos e mais ligações $\mathrm{OH}$ para o de 180 minutos, nos leva a indicar que inicialmente que toda a glicerina reagiu com o caulim e posteriormente a glicerina reagiu com o ácido succínico deixando grupos $\mathrm{OH}$ ainda livres. Esta reação entre a glicerina e o ácido succínico é confirmada pela presença de grupos ésteres que ainda não existiam no material analisado. O produto desta reação é um material polimérico proveniente da propagação da cadeia entre a glicerina e o ácido succínico.

A segunda analisada foi a série 2, composta pelas amostras G0:1_30, G0:1_180, caulim e ácido succínico. O gráfico desta séria é apresentada pela Figura 9. 


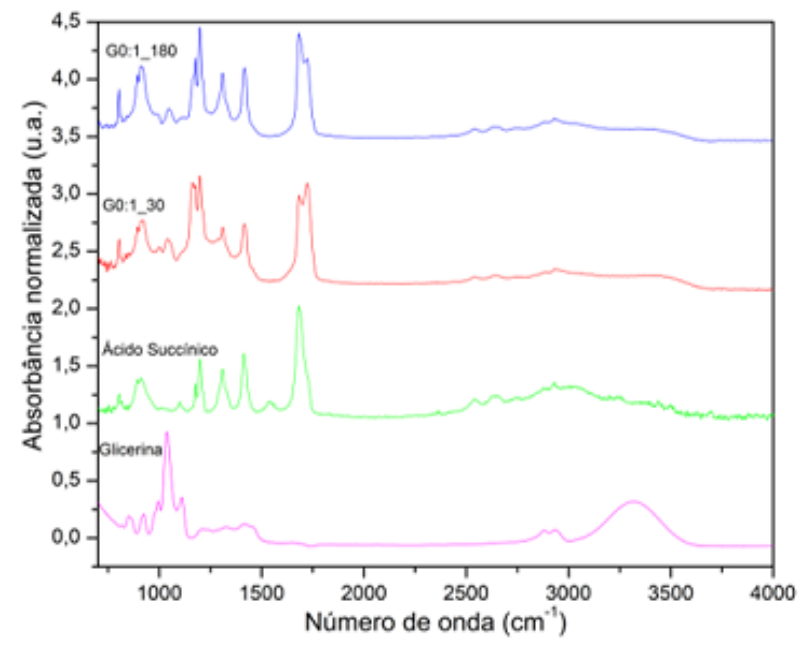

Figura 9: Espectros da Série 2

Observando os espectros de FTIR da série 2, pode-se observar a existência de uma forte banda em $1700 \mathrm{~cm}^{-1}$, característica do ácido succínico. Com 30 minutos de reação, observa-se que esta banda de $1700 \mathrm{~cm}^{-1}$ ainda é presente, mas também se observa o surgimento de uma banda em $1750 \mathrm{~cm}^{-1}$. Esta segunda banda, é característica da ligação $\mathrm{C}=\mathrm{O}$ de éster, indicando assim que aconteceu a reação e a formação de ligações éster que não existiam no ácido succínico. Com 180 minutos de reação, nota-se que a banda em $1700 \mathrm{~cm}^{-1}$ se torna mais forte, indicando uma diminuição das ligações $\mathrm{OH}$ (característico de grupos terminais da glicerina) e também um aumento das ligações glicerina-ácido succínico (GLI-AS).

A terceira analisada foi a série 3, composta pelas amostras G1:0_30, G1:0_180, caulim e ácido succínico. O gráfico desta séria é apresentada pela Figura 10.

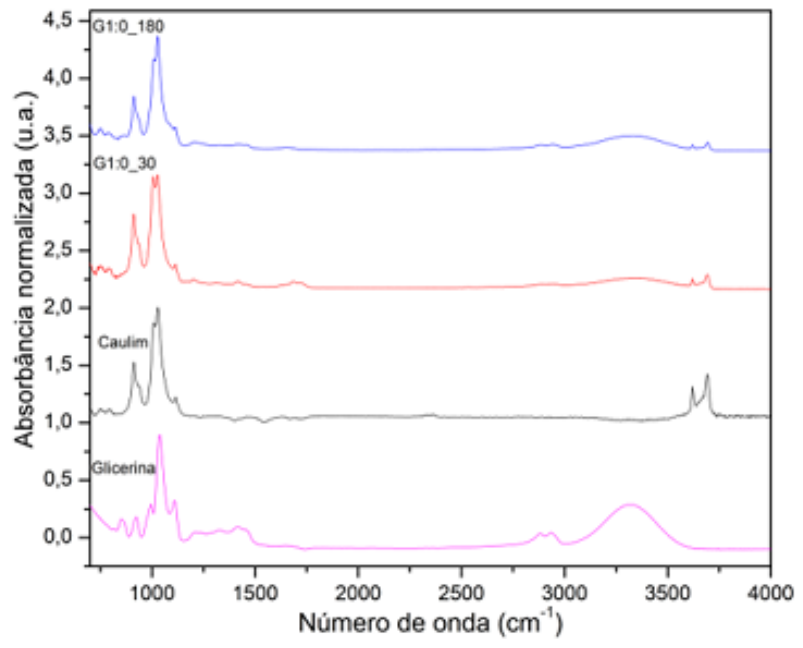

Figura 10: Espectros da Série 3

A partir dos espectros da série 3, podemos afirmar que ocorreu reação entre o caulim e a glicerina, devido à presença das bandas entre 900 e $1000 \mathrm{~cm}^{-1}$, que correspondem a ligação CO de éter. Com esta reação, é esperado encontrar grupos $\mathrm{CO}$ do caulim ligados à glicerina.

$\mathrm{Na}$ faixa entre $3000-3600 \mathrm{~cm}^{-1}$ observa-se que existem grupos Si-OH e Al-OH provenientes do caulim. Entretanto, ocorre a diminuição destas hidroxilas livres de acordo com o tempo reacional. Com o tempo de 30 minutos de reação, observamos a existência mais intensa em aproximadamente $3600 \mathrm{~cm}^{-1}$ correspondente a hidroxila livre do caulim. Com 180 minutos de reação, observa-se que estas hidroxilas livres diminuem e concomitantemente ocorre o aumento das hidroxilas em ligação de hidrogênio em $3300 \mathrm{~cm}^{-1}$, característica da glicerina. Com isso, verifica-se que existem grupos existem mais grupos Si-OH e Al-OH que interagem com a glicerina. Esta interação se dá além da mistura física destes dois materiais por também pela reação que acontece entre eles, aumentando o potencial de absorção de água devido ao aumento dos grupos $\mathrm{OH}$. 
Com as amostras finalizadas, foi feita uma análise da absorção de água, a fim de avaliar este novo material para este uso. Inicialmente foi realizado um teste de absorção somente com algodão e depois foram adicionadas as amostras sendo descontado a absorção do algodão delas. Os dados do teste de absorção são apresentados na Tabela 5. Como os testes foram realizados em triplicata, os resultados apresentados são resultados de uma média aritmética simples dos dados obtidos com um desvio padrão de até 5\%.

Tabela 5: Resultados obtidos no teste de absorção

\begin{tabular}{c|c|c|c|c|c|c}
\hline Amostra & $\begin{array}{c}\text { Massa } \\
\mathbf{( g )}\end{array}$ & $\begin{array}{c}\text { Algodão } \\
\mathbf{( g )}\end{array}$ & $\begin{array}{c}\text { Água início } \\
\mathbf{( g )}\end{array}$ & $\begin{array}{c}\text { Água final } \\
\mathbf{( g )}\end{array}$ & $\begin{array}{c}\text { Massa } \\
\text { Absorvida } \\
\mathbf{( g )}\end{array}$ & $\begin{array}{c}\text { Água } \\
\text { absorvida/amostra } \\
\mathbf{( g / g )}\end{array}$ \\
\hline G1:1_30 & 0,0222 & 0,0105 & 1,0209 & 0,8112 & 0,2097 & $9,5 \pm 0,9$ \\
\hline G1:1_180 & 0,0221 & 0,0117 & 1,0127 & 0,7874 & 0,2254 & $10,2 \pm 1,6$ \\
\hline G1:0_30 & 0,0220 & 0,0109 & 1,0250 & 0,8004 & 0,2247 & $10,1 \pm 2,3$ \\
\hline G1:0_180 & 0,0242 & 0,0124 & 1,0272 & 0,7736 & 0,2536 & $10,4 \pm 1,0$ \\
\hline G0:1_30 & 0,0223 & 0,0109 & 1,0258 & 0,7888 & 0,237 & $10,6 \pm 2,0$ \\
\hline G0:1_180 & 0,0214 & 0,0114 & 1,0244 & 0,7918 & 0,2326 & $10,9 \pm 2,4$ \\
\hline
\end{tabular}

Com o teste de absorção de água, pode-se concluir que o sistema contendo apenas o algodão, reteve cerca de 13,5 \pm $1,4 \mathrm{~g}$ de água/ g de algodão. Utilizando as amostras produzidas, observa-se que com as amostras foi possível reter cerca de $10 \mathrm{~g}$ de água/ $\mathrm{g}$ de material adicionado, descontando a massa que somente o algodão reteve. Isto significa que, as amostras são capazes de reter aproximadamente cerca de 1000 vezes a massa delas de água. A amostra que apresentou uma melhor absorção foi a G0:1_180, que reteve cerca de 10,9 $\pm 2,4 \mathrm{~g}$ da água/ $\mathrm{g}$ de material. Sendo assim, podemos observar que todas as amostras são capazes de absorver água entre 950 e $1100 \%$ de sua massa.

A análise estatística foi realizada através do software R [19], inicialmente através do teste de Shapiro-Wilk, mostrou que todas as amostras (30 e 180 minutos) seguiam a normalidade. Considerando que adotamos que a significância $(\alpha)$ foi de $0,05(5 \%)$ e o nível de confiança $(1-\alpha)$ foi de $0,95(95 \%)$. Inicialmente temos a hipótese nula $\left(\mathrm{H}_{0}=\right.$ os dados seguem a normalidade) e a hipótese alternativa ( $\mathrm{H}_{1}=$ os dados não seguem uma normalidade), e iremos verificar se existem argumentos para se rejeitar a hipótese nula. Realizado o teste de Shapiro-Wilk, compara-se o p-valor com o nível de significância $(\alpha)$, se ele for maior que que $\alpha$ não se rejeita $\mathrm{H} 0$, caso ele seja menor, rejeita-se $\mathrm{H}_{0}$ [20]. Agora é realizado o teste $\mathrm{t}$ de Student, que consiste em comparar as médias entre os grupos e verificar se elas são estatisticamente iguais. Adotamos que a significância $(\alpha)$ foi de $0,05(5 \%)$ e o nível de confiança $(1-\alpha)$ foi de $0,95(95 \%)$. Inicialmente temos a hipótese nula (H0 = as médias $\mu 1$ e $\mu 2$ são iguais) e a hipótese alternativa (H1 = as médias $\mu 1$ e $\mu 2$ não são iguais), e iremos verificar se existem argumentos para se rejeitar a hipótese nula. Realizado o teste t de Student, compara-se o p-valor com o nível de significância $(\alpha)$, se ele for maior que que $\alpha$ não se rejeita H0, caso ele seja menor, rejeita-se H0 [21]. Com o teste de t de Student, confirmamos então que as médias das amostras eram estatisticamente iguais, como pode ser observado pela Tabela 6 .

Tabela 6: Resultados do teste estatístico de Shapiro-Wilk e t de Student

\begin{tabular}{c|c|c}
\hline Amostras & Shapiro-Wilk (p-valor) & T de Student (p-valor) \\
\hline G1:1_30 e G1:1_180 & 0,6966 e 0,2502 & 0,5552 \\
\hline G1:0_30 e G1:0_180 & 0,1521 e 0,4939 & 0,862 \\
\hline G0:1_30 e G0:1_180 & 0,9972 e 0,9907 & 0,8679 \\
\hline
\end{tabular}

Após a realização deste teste estatístico, pode-se confirmar que as médias são estatisticamente iguais e com isso temos que o tempo reacional ele resulta em diferentes mudanças estruturais nas amostras, mas estas mudanças não alteram a capacidade de absorção do material.

\section{CONCLUSÕES}

Para as amostras com razão molar de 1:1, através da análise de FTIR observam-se algumas modificações nas superfícies do caulim e do ácido succínico, evidenciando a formação de ligações éster (GLI-AS-GLI) para o tempo reacional de 30 minutos e para 180 minutos a formação de grupos COOH terminais (GLI-AS). Existe também a presença de grupos Si-OH 
e Al-OH que não reagiram com a glicerina. Com a análise dos difratogramas de raios-X, observamos algumas modificações na estrutura do caulim. Quando observamos o desaparecimento dos picos entre $2 \theta=19,96^{\circ}-21,35^{\circ}$ (característicos do caulim) e o surgimento de um pico mais forte em aproximadamente $2 \theta=20^{\circ}$ (característico do ácido succínico), para a amostra G1:1_30, fica evidente que a glicerina presente no meio reacional, inicialmente reagiu preferencialmente com o caulim. Com a amostra G1:1_180, observa-se que este pico em $2 \theta=20^{\circ}$ reduz sua intensidade assim como sua largura, ficando um pouco com a característica do caulim. Com isso, observa-se o consumo do ácido succínico que até então estava em excesso no meio reacional. Este fato fica comprovado pelos espectros de FTIR destas amostras, onde observa-se para o tempo de 30 minutos a diminuição dos picos referentes a hidroxila e posteriormente, em 180 minutos, estes picos voltam a surgir.

Com as amostras de razão molar 0:1, através da análise de FTIR pode-se observar também as alterações na superfície do ácido succínico para ambos os tempos reacionais. Pode-se observar a existências de ligações $\mathrm{C}=\mathrm{O}$ de éster e ácido carboxílico, sendo cada uma mais intensa para os tempos de 30 e 180 minutos, respectivamente. Pela análise dos difratogramas de raios-X podemos observar que a amostra conserva as características cristalinas do ácido succínico sofrendo pequenas alterações como aumento e redução de alguns picos.

Para a amostras com razão molar 1:0, através da análise de FTIR observa-se a interação entre a glicerina e o caulim para ambos os tempos reacionais. Para 30 minutos de reação, existem mais grupos Si-OH e Al-OH disponíveis e com 180 minutos observa-se uma diminuição destes grupos livres e um aumento dos grupos Si-O-GLI-OH e Al-O-GLI-OH, comprovando assim a reação e a modificação da superfície do caulim. A análise dos difratogramas de raios-X mostra que as amostras mantiveram as características do caulim, sofrendo pequenas alterações em sua estrutura.

Com o primeiro teste de absorção, pode-se verificar que o material produzido foi capaz de absorver cerca de $10 \mathrm{~g}$ de água/g de material. Sendo assim, os materiais absorvem água entre 950 e $1100 \%$ de sua massa. Então, estes materiais podem ser utilizados como material filtrante para a purificação do biodiesel. O teste de absorção das amostras produzidas utilizando o amido juntamente com os materiais obtidos via a reação pelo Dean-Stark, mostrou que estes materiais podem absorver cerca 55,2 $\pm 0,7 \mathrm{~g}$ de água/g de material.

Além de poderem ser utilizados como material absorvente para o processo de purificação do biodiesel, estes materiais apresentam um grande potencial de aplicação para a produção de material absorvente em fraldas descartáveis. Um ponto forte para a utilização deste material desenvolvido é que existe uma grande oferta de caulim que é impróprio para a indústria do papel devido ao fato de este possuir um grande teor de ferro em sua composição. Sendo assim, a utilização deste material desenvolvido, além de propor utilização da glicerina bruta, coproduto da produção do biodiesel, ainda propõem a utilização de um mineral que é extraído, mas que não possui grande aplicação no mercado.

\section{AGRADECIMENTOS}

MBM Minérios, UFVJM, LPP-JEQUI, BIOMAT

\section{BIBLIOGRAFIA}

[1] TEIXEIRA, I., M., V., O uso da avaliação ambiental estratégica no planejamento da oferta de blocos para exploração e produção de petróleo e gás natural no Brasil: Uma proposta, Tese de D. Sc., Universidade Federal do Rio de Janeiro, Rio de Janeiro, RJ, Brasil, 2008.

[2] ANP - AGÊNCIA NACIONAL DO PETRÓLEO, Anuário estatístico brasileiro do petróleo, gás natural e biocombustíveis 2019. Ministério de Minas e Energia, Brasil, 2019.

[3] ANEEL - AGÊNCIA NACIONAL DE ENERGIA ELÉTRICA, Atlas de Energia Elétrica do Brasil. $3^{a}$ edição, Brasília, 2008.

[4] OLIVEIRA, P. A., Formação de derivados do glicerol em regime contínuo, Dissertação de M. Sc., Escola de Química, Universidade Federal do Rio de Janeiro, Rio de Janeiro, RJ, Brasil, 2015.

[5] BRASIL; Lei no 9.478 de 6 de agosto de 1997, Diário Oficial da União, 1997.

[6] FACCINI, C. S., Uso de Adsorventes na Purificação de Biodiesel de Óleo de Soja, Dissertação de M. Sc., Instituto de Química, Universidade Federal do Rio Grande do Sul, Porto Alegre, RS, 2008.

[7] MOTA, C. J. A., PESTANA, C. F. M., "Coprodutos da produção de biodiesel”, Revista Virtual de Química, v. 3, n. 5, pp. 416 - 425, Oct. 2011.

[8] MENDES, D. B., SERRA. J. C. V., “Glicerina: uma abordagem sobre a produção e o tratamento”, Revista Liberato, v. 13, n. 20, p. 01-09, 2012. 
[9] BARATA, M. S., Aproveitamento dos resíduos cauliníticos das indústrias de beneficiamento de caulim da região amazônica como matéria-prima para fabricação de um material de construção (pozolanas), 2007, 366 f.; Tese de D. Sc - Instituto de Geociências, Universidade Federal do Pará, 2007.

[10] ARAÚJO, J. C., ASSIS, J. T., MONINE, V. I., BERTOLINO, L. C., "Caracterização da Microestrutura de Caulinitas pela Difração de Raios X”, Revista Matéria, v. 11, n. 3, pp. 361 - 371, 2006.

[11] BARATA, M. S., ANGÉLICA, R. S., "Atividade pozolânica dos resíduos cauliníticos das indústrias de mineração de caulim da Amazônia”, Revista Matéria, v. 16, n. 3, pp. 795 - 810, 2011.

[12] MBM Minérios, "Certificado de análise”, 2017.

[13] BARBOSA, L. C. A., Espectroscopia no infravermelho na caracterização de compostos orgânicos, $1^{\text {a }}$ edição. Viçosa, MG. Ed. UFV, 2007.

[14] PAVIA, D. L., LAMPMAN, G. M., KRIZ, G. S., VYVYAN, J. R., Introdução à Espectroscopia. 4ª edição. São Paulo, SP. Ed. Cengage Learning, 2010.

[15] SAIKIA, B. J., PARTHASARATHY, G., "Fourier transform infrared spectroscopic characterization of kaolinite from Assam and Meghalaya, northeastern Índia”, Journal of Modern Physics, v. 1, pp. 206 - 210, Oct. 2010.

[16] DIKO, M., EKOSSE, G., OGOLA, J., "Fourier transform infrared spectroscopy and thermal anal-yses of kaolinitic clays from south africa and Cameroon", Acta Geodynamica et Geomaterialia, v. 13, n. 2, pp. 149 - 158, Dec. 2015.

[17] KRISHNAN, C., RAJ, C. J., ROBERT, R., et al. "Growth and characterization of succinic acid single crystals", Crystal Research and Technology, v. 42, n. 11, pp. 1087 - 1090, Nov. 2007.

[18] MITRA, T., SAILAKSHI, G., GNANAMANI, A., MANDAL, A. B., "Studies on cross-linking of succinic acid with chitosan/collagen”, Materials Research, n. 16, pp. 755 - 765, Dec. 2012.

[19] R Core Team (2019). "R: A language and environment for statistical computing. R Foundation for Statistical Computing", Vienna, Austria. URL https://www.R-project.org. Acessado em: maio de 2019.

[20] PORTAL ACTION, 6.4 - Teste de Shapiro-Wilk. http://bit.ly/30wZwG9. Acessado em maio de 2019.

[21] PORTAL ACTION, 5.2 - Teste para média (t teste). http://bit.ly/2QcKUah. Acessado em maio de 2019.

\section{ORCID}

Wilker Tagner do Nascimento Mendes

Juan Pedro Bretas Roa

Edivaldo dos Santos Filho https://orcid.org/0000-0003-4654-6159

https://orcid.org/0000-0002-0045-3953

https://orcid.org/0000-0001-7287-3909 